\title{
Shoulder Condition in the Treatment of Ilizarov Fractures of the Bone
}

\author{
Schurov LA* and Melnikova LV \\ Russian Ilizarov Scientific Center, Russia \\ *Corresponding author: Schurov LA, Russian Ilizarov Scientific Center, Russia \\ Submission: 觜 November 28, 2018; Published: 制 December 14, 2018
}

\begin{abstract}
The aim of the study was to determine the stiffness of fixation of bone fragments of the humerus during Ilizarov treatment, the ability of the bone regenerate to withstand the applied axial load, as well as the effect on the duration of fixation of the transfer of patients to outpatient treatment. During the treatment, 28 patients aged from 20 to 94 years $(39 \pm 3)$ with closed fractures of the diaphysis of the shoulder were re-examined. All patients after 16 days of treatment in the hospital switched to an outpatient treatment regimen.

Results: The axial load on the damaged shoulder did not exceed $20 \mathrm{~kg}$. A distinctive feature of patients with a fracture of the humerus was the fact that they did not experience a period of increase in the tensometric measurement of the micromodularity of bone fragments during outpatient treatment. The average size of the area of the X-ray shadow of periosteal callus was $153 \pm 16 \mathrm{~cm} 2$, while the elderly and old age did not have a limiting effect on periosteal corn formation, which shortened the treatment time. The duration of the fixation period reached $82 \pm 3.4$ days, which is $65 \%$ more than with inpatient treatment. Fracture of the humerus is a relatively common skeletal injury and is found in clinical practice with a frequency of 13 per 1,00,000 per year [1-3]. The incidence rate depends on age and sex with a common bimodal distribution due to peak morbidity for men aged 20 to 30 years and the second peak for women aged 60 to 70 years (mainly in the proximal bone) [4]. During osteosynthesis according to Ilizarov, the Ilizarov apparatus with the proximal and distal supports in the form of a half-ring is superimposed due to the proximity of the tissues of the proximal shoulder to the rib cage and the need to bend the forearm at the elbow joint by more than 90degrees. Consequently, the design of the external fixation device is less rigid than, for example, used in the treatment of injuries to the bones of the tibia. The recommended minimum time for fusion of fragments of the humerus are 45-55 days [5]. The aim of the study was to determine the stiffness of fixation of bone fragments, the ability of the bone regenerate to withstand the attached axial load and the ability of the vascular bed to withstand the applied loads, as well as the effect on the terms of treatment of transferring patients to an outpatient treatment.
\end{abstract}

\section{Material and Research Methods}

The study involved 28 patients aged from 20 to 94 years (mean $39 \pm 3$ ) with closed fractures of the diaphysis of the shoulder at different times after applying the Ilizarov apparatus. All patients after 16 days of treatment in the hospital switched to an outpatient treatment regimen. Using a sensor with a carrier frequency of $8 \mathrm{MHz}$ of the computerized diagnostic complex Angiodin-2KM of the production association BIOSS (Russia), the blood flow velocity was recorded in the regeneration zone along the outer shoulder surface with a stepwise axially directed functional loading of the limb segment [6]. In all patients, the maximum allowable functional load on the injured limb was determined using floor scales (Figure 1). In addition, when using a strain gauge and a B7-73/1voltmeter, a strain gauge signal was recorded that allowed determining the change in the distance between the spokes coming out of the bone above and below the fracture zone, which allowed determining the micro mobility of fragments of the humerus at the axial loading metered in 5kg corresponding to limbs [7]. After the apparatus was removed, the area of the shadow of the periosteal callus was planimetrically estimated from radiographs of the shoulder. Self-assessment of the physical and mental state of patients was performed using the SF-36 test. The test card put into a computer contains 36 alternative questions that, based on 8 modules, allow us to judge the quality of life by integrating physical data (efficiency, ability to self-care, well-being, pain ) and mental state (vitality, mood, emotional state, social activity) of the subject. Each of the modules evaluated as a result is an indicator containing from 0 to 100 points [8]. When processing the research materials, standard statistical programs were used that allow the use of parametric research methods with the analysis of indicators of the reliability of differences in independent Student's samples, incorporated in the "Microsoft Office Excel 2010" package. Average values are given in combination with standard deviation. The graphs show the magnitude of the reliability of the results (when approximation, the coefficient of determination $\mathrm{R}^{2}$ is given).

\section{Results and Discussion}

The maximum permissible functional load on the shoulder increased during the first month of treatment from 5 to $20 \mathrm{~kg}$ and subsequently remained at this level. The micro mobility of bone fragments in the process of treatment has steadily decreased, including after the transfer of patients to the outpatient regimen (Figure 2). 


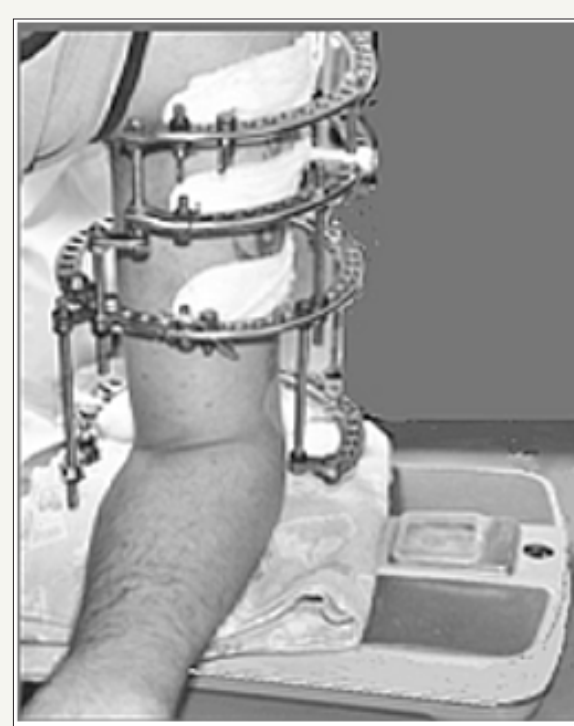

Figure 1: Work moment determination of axially directed functional load on the shoulder.

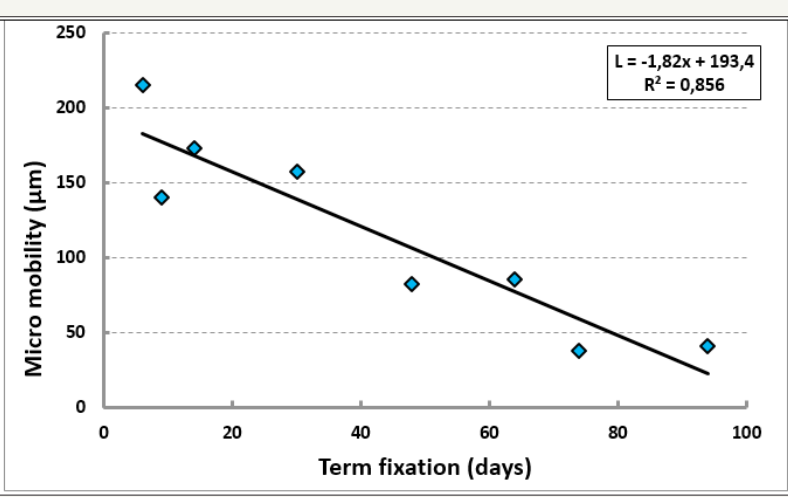

Figure 2: Dependence of the rigidity of fixation of fragments on the timing of fixation.

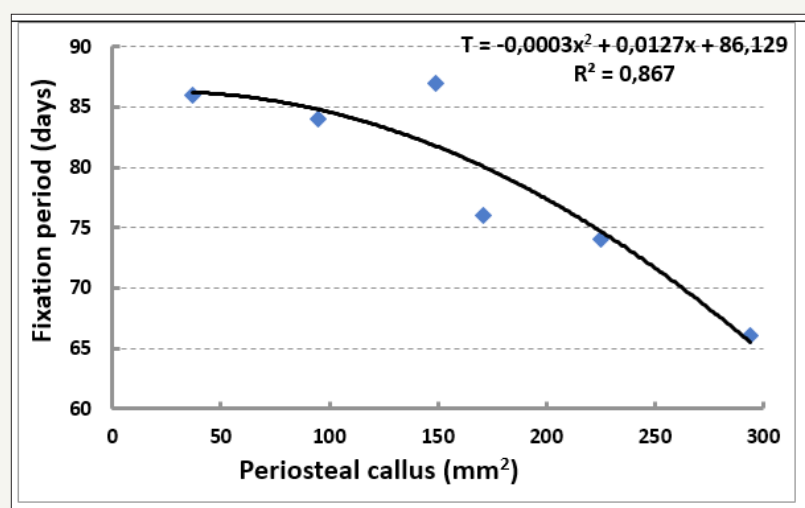

Figure 3: Dependence of the duration of the fixation period on the value of the periosteal callus.

The micro mobility of fragments at the beginning of treatment is determined by the rigidity of the structure of the external fixation apparatus, and in the second half of the fixation period, by the condition of the callus consisting of endosteal, intermedial, and periosteal parts. Indeed, the larger the size of the periosteal callus, the shorter the fixation period (Figure 3). It is known that the periosteal callus is formed in addition to the enchondral and intermediary with insufficient fixation of bone fragments and itself provides their stabilization.

The periosteal callus of the humerus is easily formed in young and old, when the mass of bone mass is relatively less than in 40-60 years (Figure 4).

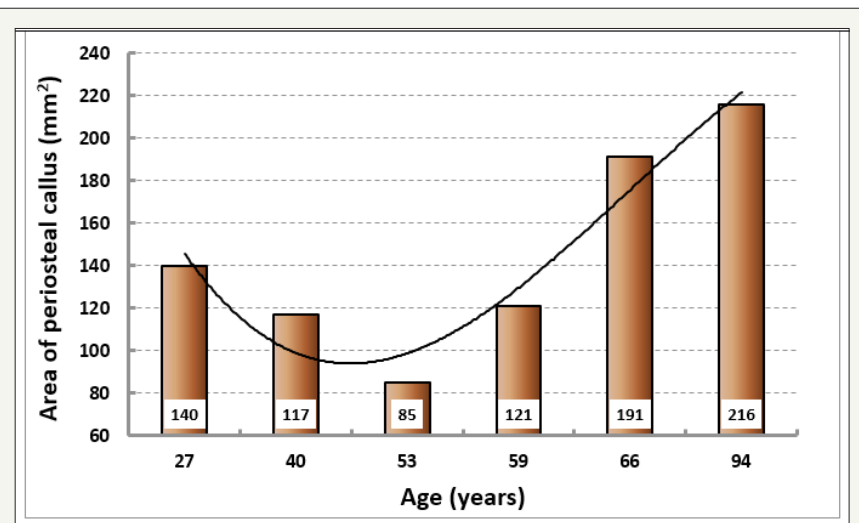

Figure 4: The age dynamics of the size of the periosteal callus of the shoulder.

Linear systolic blood flow velocity in the arteries of the bone regenerate, increased in the first 3 weeks of treatment, decreases (Figure 5). This decrease is characteristic for the transition of the catabolic phase of metabolic processes in tissues to anabolic, which contributes to the compaction of bone regenerate.

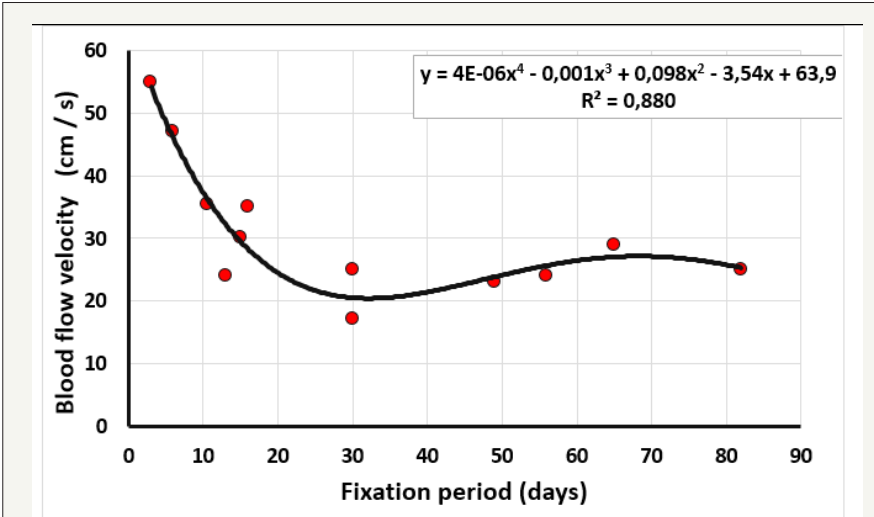

Figure 5: Dynamics of blood flow velocity in the arteries of the regenerate in the treatment of patients.

The linear velocity of blood flow increases from 33 to $39 \mathrm{~cm} / \mathrm{s}$ with increasing micro mobility of bone fragments from 0 to 150 microns. In order to accelerate blood flow and tissue metabolism during osteosynthesis, various methods of dynamization of bone fragments are used [9-12]. However, too large micro mobility of fragments is unfavorable for the blood supply to the bone regenerate (Figure 6).

The linear velocity of blood flow depends not only on the level of tissue metabolism, the stiffness of fixation of fragments, but also on the lumen of arterioles and arteries. With the functional load 
on the limb as the pressure in the regenerate increases, the blood flow velocity decreases due to compression of micro vessels with relatively low pressure. But when the pressure in the tissues begins to exceed the level of transmural in the walls of the arteries - the linear velocity of the blood flow rises (Figure 7). Patients have discomfort, forcing to abandon the further implementation of the functional test. The longer the fixation period, the later the increase in blood flow velocity occurs, and accordingly the recorded load on the limb is higher (Figure 8).

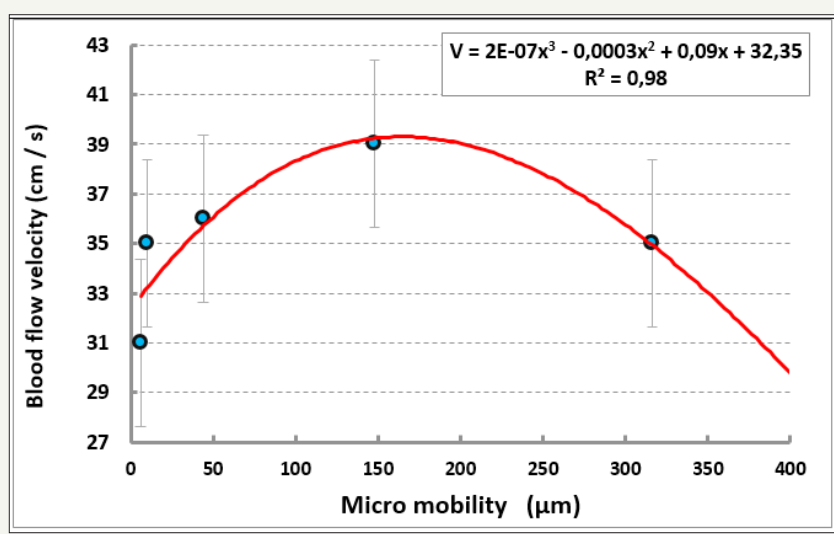

Figure 6: The relationship of blood flow velocity and the magnitude of the micro mobility of bone fragments.

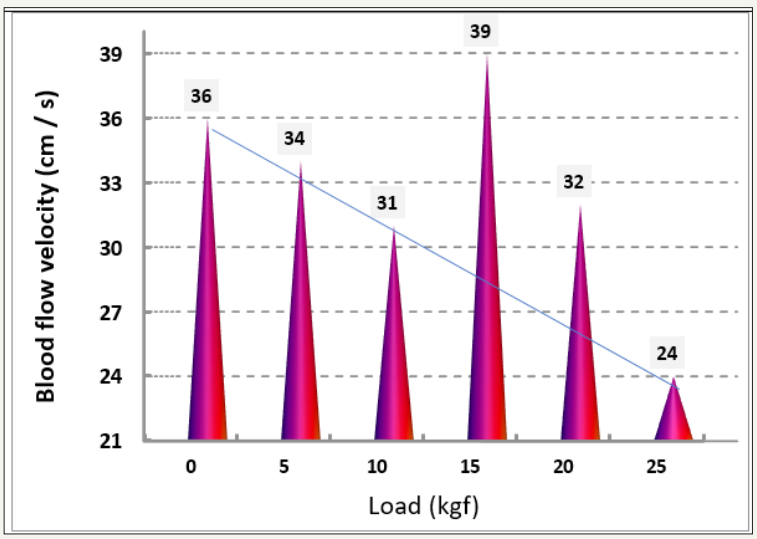

Figure 7: The effect of axial load on the shoulder on the speed of blood flow in the arteries of the regenerate.

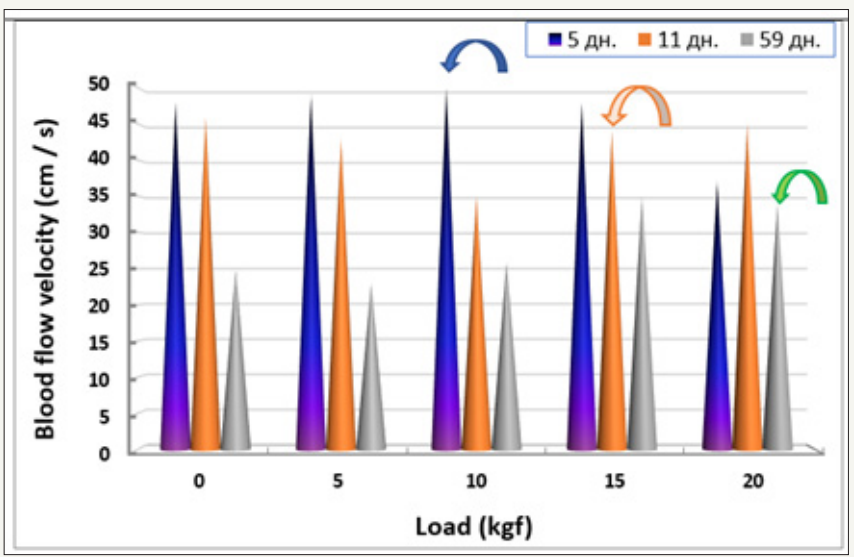

Figure 8: Dynamics of blood flow velocity in the regenerate under load in the 1st, 2 st and 9th weeks of the fixation period.

Thus, if patients with fractures of the lower limbs from 3 weeks of treatment can walk with support on the injured limb, the axial load on the injured shoulder is relatively 2-3 times less. A distinctive feature of patients with a fracture of the humerus was the fact that they did not have a period of increased micro mobility of bone fragments during outpatient treatment. The average size of the periosteal callus was $153 \pm 16 \mathrm{~cm}^{2}$, which is comparable with the ratio of the sizes of the periosteal callus and the diameter of the tibia. 
The duration of the fixation period reached an average of $82 \pm 3.4$ days, increasing as well as for fractures of the shin bones by $65 \%$ compared with the duration of treatment in stationary conditions. In this case, the periosteal reaction in elderly and senile people with damage to the humerus did not become less pronounced.

\section{References}

1. Brown CCM, Caesar B (2006) Epidemiology of adult fractures: A review. Injury 37(8): 691-697.

2. Strong TG, Walls N, McQueen MM (1998) The epidemiology of humeral shaft fractures. J Bone Joint Surg Br 80(2): 249-253.

3. Heineman DJ, Bhandari M, Nork SE, Ponsen KJ, Poolman RW (2010) Treatment of humeral shaft fractures meta-analysis reupdated. Acta Orthop 81(4): 517

4. Igbigbi PS, Manda K (2004) Epidemiology of humeral fractures in Malawi. Int Orthop 28(6): 338-341.

5. Ilizarov GA (1990) Transosseous osteosynthesis /Theoretical and clinical aspects of the regeneration and growth of tissue. SpringerVerlag, Germany, p. 799.
6. Schurov VA (2017) Cerebral hemodynamic autoregulation in the clinic of traumatology and orthopedics. Moscow Publisher, Russia, p. 114.

7. Schurov VA (2014) Elastic compliance and blood supply of the distraction regenerate. Russian Journal of Biomechanics 4: 471-478.

8. Hopman WM, Towheed T, Anastassiades T, Tenenhouse A, Poliquin S, et al. (2000) Canadian normative data for the SF-36 health survey. Canadian Medical Association or its licensors 163(3): 265-271.

9. Berquist TH (2018) Authorship Resisted: Part 1. reparation for submission to AJR. American Journal of Roentgenology 211(4): 715-716.

10. Claes LE, Heigele CA, Wilke NC, Kaspar D, Seidl W, et al. (1998) Effects of mechanical factors on the fracture healing process. Clin Orthop Relat Res 355: S132-147.

11. Kenwright J, Goodship AE (1989) Controlled mechanical stimulation in the treatment of tibial fractures. Clin Orthop Relat Res 241: 36-47.

12. Yamaji T, Ando K, Wolf S, Augat PR, Claes L (2001) The effect of micromovement on callus formation. Journal of Orthopaedic Science 6(6): 571-575.
Creative Commons Attribution 4.0

International License

For possible submissions Click Here
Submit Article

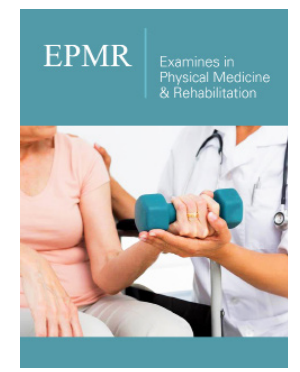

Examines in Physical Medicine and Rehabilitation: Open Access

\section{Benefits of Publishing with us}

- High-level peer review and editorial services

- Freely accessible online immediately upon publication

- Authors retain the copyright to their work

- Licensing it under a Creative Commons license

- Visibility through different online platforms 